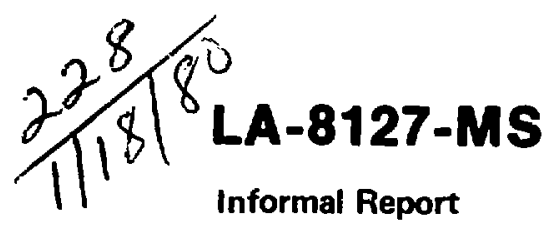

$\frac{1}{4}$

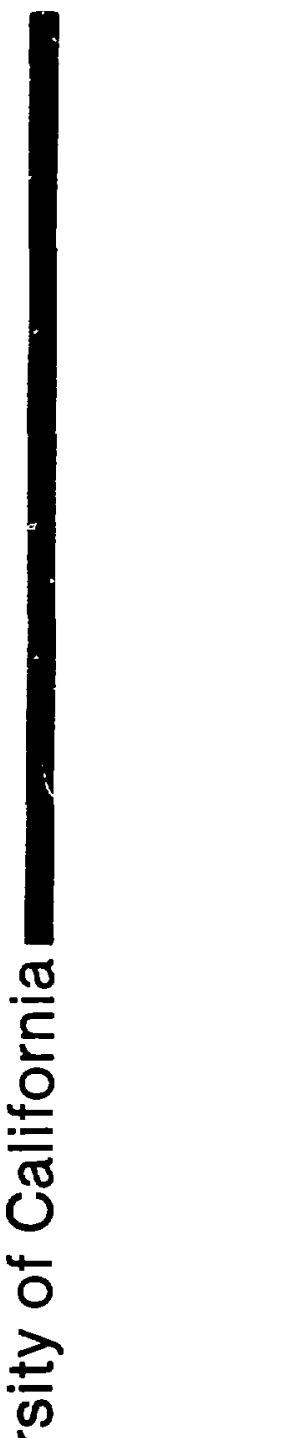





㐫

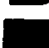

\title{
Defect Formation in 800-MeV Proton-Irradiated Aluminum
}

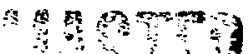

$\therefore \therefore-3 \div$ 
LA-8127-MS

Informal Report

UC-25

Issued: November $19{ }^{\circ}$

\title{
Defect Formation in 800-MeV Proton-Irradiated Aluminum
}

\author{
H. Jang* \\ J. Moteff* * \\ L. Levinson \\ R. D. Brown \\ W. V. Green
}

"Aircraft Engire Group, General Electric Co., Cincinnati, OH 45215.

" "Short-term Visiting Staff Member. Department of Materials Science and Metallurgical Engineering, University of Cincinnati, Cincinnati, OH 45221.
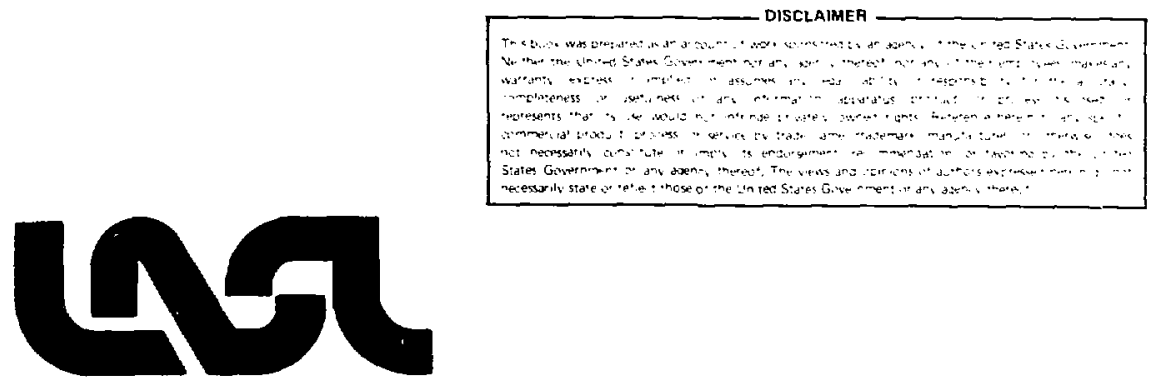


\title{
DEFECT FORMATION IN 800-MeV PROTON-IRRADIATED ALUMINUM
}

\author{
by
}

\author{
H. Jang, J. Moteff, L. Levinson, \\ R. D. Brown, and W. V. Green
}

\begin{abstract}
Transmission electron microscopy was used to investigate the formation of irradiation-induced defects in proton-irradiated high-purity aluminum. The specimens were irradiated by $800-\mathrm{MeV}$ protons to about 0.25 displacements per atom (dpa) in the Los Alamos Meson Physics Facility (LAMPF), producing about 20 atomic ppm helium, 130 atomic ppm hydrogen, and approximately 70 atomic ppm of spallation products. The as-irradiated microstructure mainly consisted of cavities with a mean size of $88 \mathrm{~A}$, number density of $1 \times 10^{15} \mathrm{cavities} / \mathrm{cm}^{2}$, and volume fraction of atsout $0.05 \%$. The swelling was comparable to that of high-purity aluminum samples neutronirradiated to the same displacement level. However, the high production rate of gas atoms during the proton irradiation increased the cavity number density by an order of magnitude relative to neutron irradiation, and reduced the cavity size by a factor of about 3 . A postirradiation annealing treatment at $250^{\circ} \mathrm{C}$ resulted in complete disappearance of the small cavities and formation of gas bubbles on grain boundaries.
\end{abstract}

\section{INTRODUCTION}

The LAMPF accelerator offers a beam of 800 $\mathrm{MeV}$ protons at a design current of $1 \mathrm{~mA}$. The high proton energy allows uniform damage production in thick (several centimeters) targets. At several locations in the experimental area, the beam is focused to form a beam several millimeters across, allowing very high damage rates to be achieved. These irradiation conditions could make $800-\mathrm{MeV}$ protons a useful tool in studying the effects of radiation on mechanical properties. In addition, such studies would provide information on radiation effects to LAMPF structures such as windows, targets, and beam stops which are irradiated at lower fluxes for long periods.

A theoretical analysis of displacement damage was made by Coulter et al. for 1-cm-thick copper ${ }^{1}$ and aluminum ${ }^{2}$ targets irradiated with $800-\mathrm{MeV}$ protons. Only a fraction of the primary beam interacts significantly with the target nuclei, producing secondary charged particles which are mostly absorbed within the target, while the primary beam is not stopped. Nuclear theory was used to calculate the number and energy of secondary particles. The resulting damage energy cross sections and spallation atom cross sections were used to calculate displacement rates and production rates of hydrogen, 
helium, and spallation imp'irity atoms. The calculated displacement rate is large, up to 0.5 displacements per atom (dpa) per day in aluminum at locations where the beam is focused down to its smallest size, i.e., a few millimeters across. And the beam heating per dpa is less than with most simulation techniques. The displacement rate is essentially constant for specimens up to several centimeters thick. The majority of the displacements $(98 \%)$ are produced by energetic heavy spallation impurity atoms. The spallation nucleus recoil energy spectrum shows a peak at about $50 \mathrm{keV}$, a high energy tail, and an average energy of $2 \mathrm{MeV}$ in copper.

\section{EXPERIMENTAL PROCEDURE}

Marz-grade aluminum ( $99.999 \%$ purity) specimens, approximately $0.25 \mathrm{~mm}$ thick and $3 \mathrm{~mm}$ diameter, were irradiated to a dose of about 0.25 dpa with $800-\mathrm{MeV}$ protons in the Los Alamos Meson Physics Facility (LAMPF). Aluminum samples were chosen rather than copper because even at ambient temperature $\left(20^{\circ} \mathrm{C}\right)$ the aluminum would be in the temperature range for void growth. The specimen holder was placed in a water-cooled fixture which centered the specimens in the protcn beam. The iemperature of the fixture remained $20^{\circ} \mathrm{C}$ throughout the irradiation. It was not possible to attach a thermocouple directly to the irradiated area of the specimen. Based on the changes in void structure following a $150^{\circ} \mathrm{C}$ anneal, it is clear that the irradiation temperature was between 20 and $150^{\circ} \mathrm{C}$.

Thin foils of these specimens were prepared for transmission electron microscopy in a Fischione electropolishing apparatus by using a solution of 25$\mathrm{m} \boldsymbol{\ell} \mathrm{HNO}_{3}, 25-\mathrm{m} \boldsymbol{\ell}$ methanol, and $1-\mathrm{m} \boldsymbol{\ell} \mathrm{HCl}$ at room temperature. In order to check on the uniformity of the damage accumulation across the specimen thickness, one foil was prepared by first removing $20 \mu \mathrm{m}$ of the irradiated surface layer on one side before thinning the specimen from the other side. It was thus possible to compare the midplane to a plane lying just inside the irradiated surface. The foils were examined in a JEM $200 \mathrm{~A}$ transmission electron microscope equipped with a specimen cold finger and $30^{\circ}$ tilt- $360^{\circ}$ azimuth goniometer stage. The microscope was operated at $100 \mathrm{kV}$ during the examination of microstructures in order to minimize possible damage to the specinen by the electron beam, but was elevated to $200 \mathrm{kV}$ when photographs were taken. No electron damage was noted.

Quantitative TEM data were obtained by using a TGZ 3 Zeiss particle-size analyzer, and the specimen thickness was determined by stereomicroscopy using the following relationship.

$$
\mathrm{t}=\frac{\mathrm{P}}{2 \mathrm{M} \sin \phi},
$$

where

$$
\begin{aligned}
& \mathrm{t}=\text { specimen thickness } \\
& \mathrm{P}=\text { parallax }, \\
& \mathrm{M}=\text { magnification }
\end{aligned}
$$

and

$\phi \quad=$ one-half of the total tilting angle.

The parallax, $\mathrm{P}$, was measured at several different areas of the microgriph by using a mirror stereoscope (stereoviewer) equipped with a micrometer head and floating mark units. The cavities which appeared to be on or near the surfaces of the specimen were chosen as reference points in measuring the parallax, and the average value of the measurements was used to calculate the specimen thickness.

Postirradiation annealing treatments were carried out on two separate specimens in a vacuum of $2 \times 10^{-6}$ torr for $1 \mathrm{~h}$ at 150 and $250^{\circ} \mathrm{C}$, respectively. The specimens were then thinned for the TEM examination. The thinned foil obtained from the $250^{\circ} \mathrm{C}$ anneal treatment was subsequently reannealed at $425^{\circ} \mathrm{C}$ for $20 \mathrm{~h}$ in the same vacuum system.

\section{Results}

The as-irradiated specimens were found to contain a high concentration of cavities, joggy dislocations, black spots, and dislocation loops, A typical 
cavity structure is shown in Fig. 1. The cavities appeared to be bounded by (111) crystallographic planes with their projections in the form of squares, and were distributed fairly uniformly throughout the grain interiors. The size of the cavities varied from 40 to $180 \mathbf{A}$, and the average size was $88 \mathbf{A}$, as shown in Fig. 2. The cavity data in this figure represent about 700 cavities measured with the aid of a Zeiss particle-size analyzer on micrographs at a magnification of $150000 \mathrm{X}$. The calculated cavity concentration was $1.0 \times 10^{16}$ cavities $/ \mathrm{cm}^{2}$, and the resultant volume fraction was $0.05 \%$. The cavity distribution did not appear to be altered near the loops associated with dislocations, as shown in Figs. 3(a) and (b). On the other hand, regions adjacent to grain boundaries were denuded of cavities by about $0.2 \mu \mathrm{m}$, as shown in Fig. 3(c). The cavity size and population immediately adjacent to the denuded zones seemed to be consistent with those in regions away from the grain boundaries. Also, the overall cavity structure, i.e., size, density, and shape obtained from the regions $20 \mu \mathrm{m}$ below the

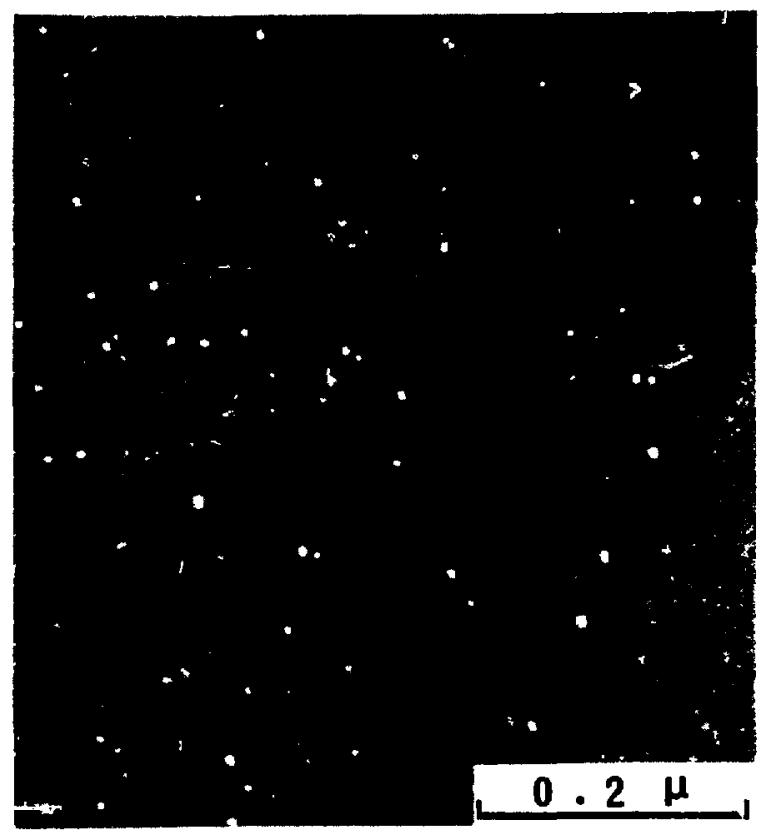

Fig. 1.

A typical cavity microstructure in Marz-grade aluminum irradiated by $800-\mathrm{MeV}$ protons to $0.25 \mathrm{dpa}$ at $20^{\circ} \mathrm{C}$. irradiated surface were seemingly identical w those obtained from the midplane of the speciuen as described ahove.

Joggy network dislocations, which seemingly developed by agglomeration and growth of radiation-induced point defects, varied remarkably in their number density from one region of the specimen to another, as shown in Figs. 4(a) and (b). The average dislocation density, determined by the random line intercept method, was about $3 \times 10^{\circ}$ $\mathrm{cm} / \mathrm{cm}^{2}$. Figure 4(c) shows dislocation loops of various sizes and black spots. The black spots were considered to be unresolvable dislocation loops, and their number density, combined with that of the resolvable loops, was about $2 \times 10^{12} \mathrm{loops} / \mathrm{cm}^{*}$. Dislocation loop-denuded zones near grain boundaries were not evident, as shown in Fig. 4(d).

Postirradiation anneal at $150^{\circ} \mathrm{C}$ for $1 \mathrm{~h}$ resulted in a reduction in the dislocation density from $3 \times 10^{9}$ $\mathrm{cm} / \mathrm{cm}^{2}$ to $1 \times 10^{\circ} \mathrm{cm} / \mathrm{cm}^{2}$, but almost no changes in

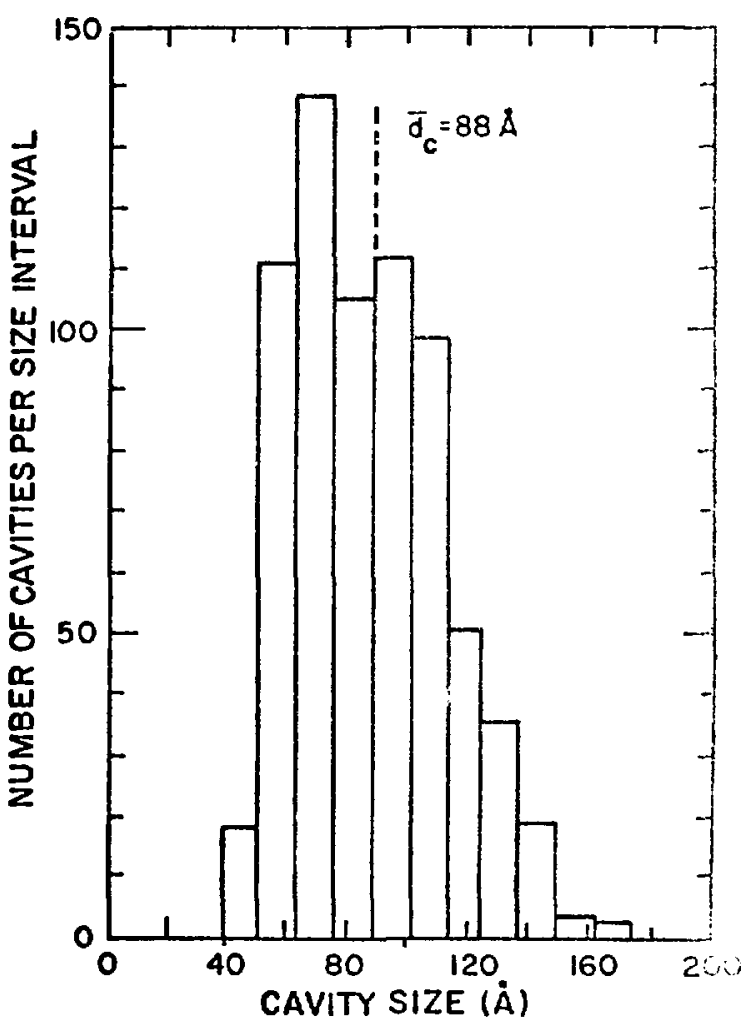

Fig. 2.

Size distribution of cavities formed in protonirradiated aluminum. 


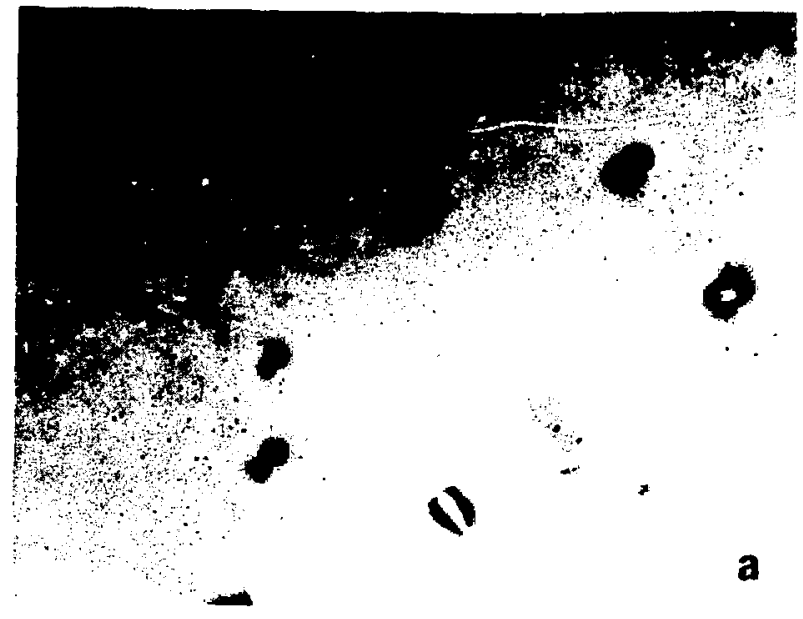

Fig. 3.

As-irradiated microstructures of protonirradiated aluminum. (a) Small black spots in the background are overfocused cavities, and the cavity distribution is not altered near the loops; (b) cavities are underfocused in this micrograph, and are not associated with the dislocations; and (c) cavity-denuded zone adjacent to a grain boundary.
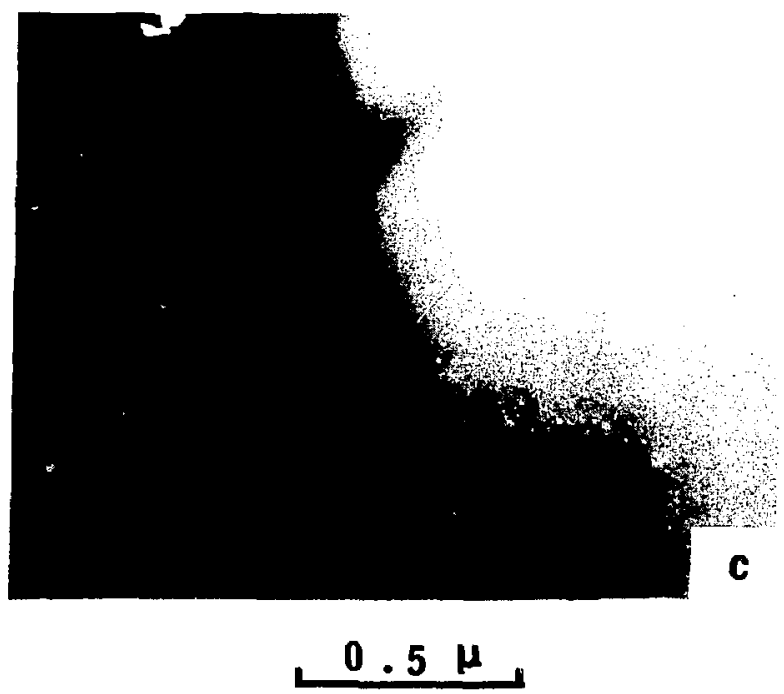

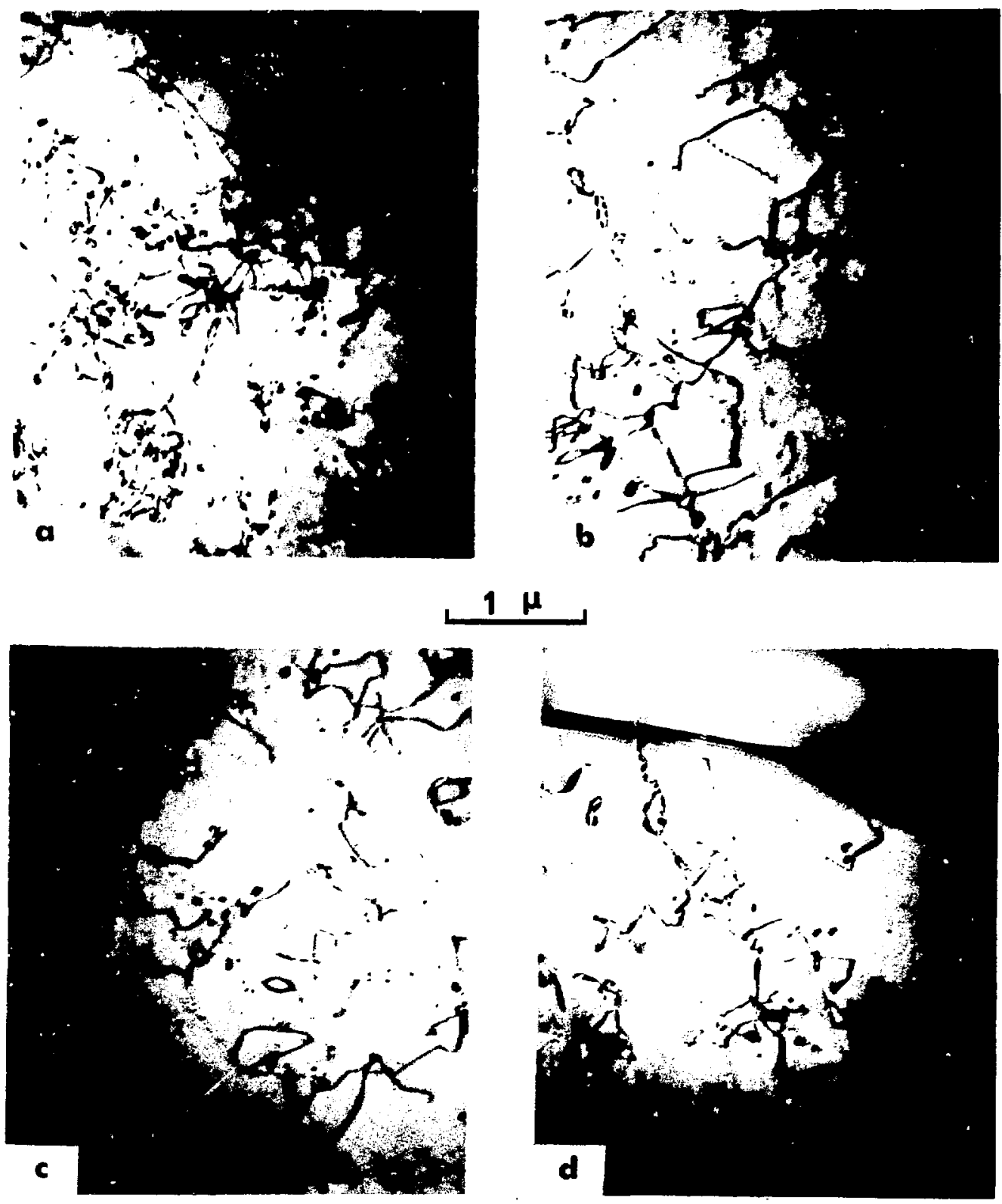

Fig. 4.

Typical dislocation structures in proton-irradiated aluminum; (a) and (b) show a large variation in dislocation density from one area of the specimen to another, (c) dislocation loops of various sizes, and (d) dislocation structures near a grain boundary.

the cavity structures, as shown in Figs. 5(a) and (b). After the anneal at $250^{\circ} \mathrm{C}$ for $1 \mathrm{~h}$, all the small cavities were annealed out, and the microstructure consisted of large cavities newly formed during the annealing treatment and coarse network dislocations, as shown in Figs. 5(c) and (d), respectively. The cavities were faceted and were observed preferentially at or near grain boundaries. The size 

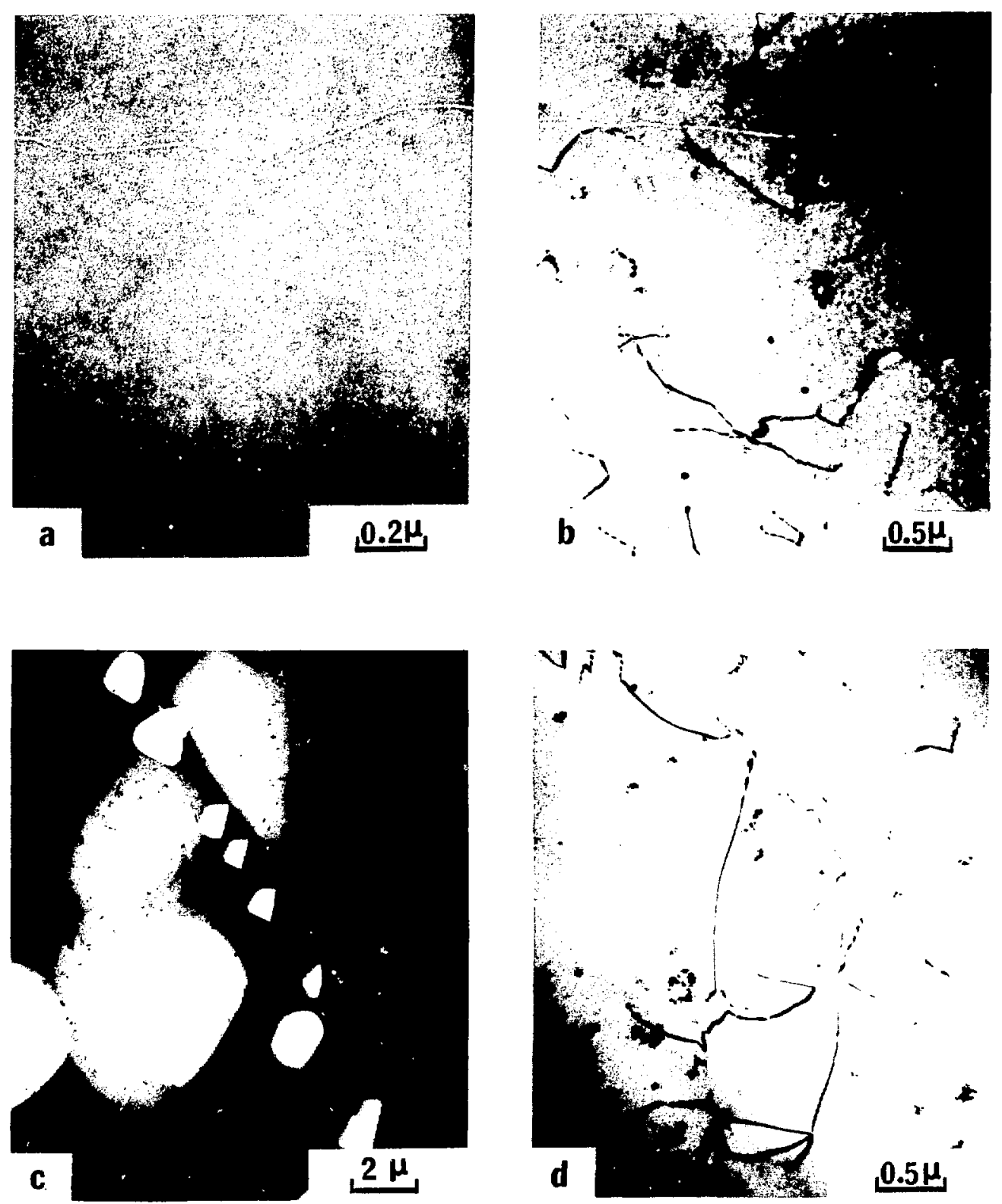

Fig. 5.

Postirradiation-annealed microstructures of proton-irradiated aluminum; $(a)$ and $(b)$ cavities and dislocations after an anneal at $150^{\circ} \mathrm{C}$ for $1 \mathrm{~h},(\mathrm{c})$ and (d) large cavities formed near grain boundaries and coarsened network dislocations after an anneal at $250^{\circ} \mathrm{C}$ for $1 \mathrm{~h}$.

of the cavities varied from about 1 to $5 \mu \mathrm{m}$, and the larger ones were cut by the foil surfaces. Upon further annealing this foil at $425^{\circ} \mathrm{C}$ for $20 \mathrm{~h}$, some of the smaller cavities disappeared, but the larger ones persisted.

Using the production cross section, it was calculated that irradiation of aluminum to $0.25 \mathrm{dpa}$ 
would generate about 20 -appm heliu $\eta$. To check the calculations, samples were analyzed using vacuum extraction by $H$. Farrar on a contract basis. Helium concentrations were observed at levels from 13 to $30 \mathrm{appm}$ on $1 \mathrm{mg}$ samples taken from an irradiated foil. The experimental variation was due to the location of the samples relative to the center of the irradiated area. This was confirmed in that measiurements of the $\beta+\gamma$ activity from each of the small samples correlated closely with the concentration of helium measured for that sample.

\section{DISCUSSION}

\section{A. The Nature of the Cavities}

As shown in Table $\mathrm{I}$, the $800-\mathrm{MeV}$ protons produce about 600 times the helium and 900 times the hydrcgen per unit of displacement damage of a fission reactor. (Since helium is almost completely insoluble in aluminum, ${ }^{3}$ it can be considered that the helium atoms will form equilibrium gas bubbles and probably reside in radiation-induced voids, because the voids are frequently assumed in the literature to be nucleated on embryonic gas bubbles and stabilized by the gas pressure.) The amount of helium produced during the present irradiation is $15-20$ atomic $\mathrm{ppm}$ as calculated by the reaction rates, and 30 atomic ppm as determined by a vacuum extraction method on an as-irradiacied specimen. If all these helium atoms reside in the cavities observed in the ab-irradiated specimen, each cavity will contain about $1100 \sim 1800$ helium atoms. On the other hand, the number of helium atoms contained in an equilibrium gas bubble can be estirsted from the simplified Van der Walls' equation as follows:

$$
\mathbf{p}(v-\not b)=\eta \mathbf{k T},
$$

where

$$
\begin{aligned}
& \mathrm{p}= 2 \gamma / \mathrm{r}, \\
& \eta= \text { number of helium atoms }, \\
& \mathrm{r}, \nu= \begin{array}{l}
\text { bubble radius and volume, respec- } \\
\text { tively },
\end{array} \\
&\left.\gamma \quad=\begin{array}{l}
\text { surface tension }(=1140 \mathrm{dynes} / \mathrm{cm} \text { for } \\
\text { aluminum }
\end{array}\right)
\end{aligned}
$$

\begin{tabular}{|c|c|c|c|}
\hline Facility & $\begin{array}{c}\text { Displacements } \\
\times 10^{6} \text { dpa } 8^{-1}\end{array}$ & $\begin{array}{c}\text { Helium } \\
\text { at. ppm He/dpa }\end{array}$ & $\begin{array}{l}\text { Hydrogen } \\
\text { at. ppm E/dpa }\end{array}$ \\
\hline LAMPF* & 2.5 & 70. & 520. \\
\hline EBR-II & 4.2 & 0.12 & 0.6 \\
\hline UWMAK-I, First Wallc & 0.9 & 15. & 12. \\
\hline
\end{tabular}

and

TABLE I. REACTION RATES FOR HIGH-ENERGY PROTONS,
EBR-II AND UWMAK-I IN ALUMINUM

${ }^{2} 800-\mathrm{MeV}$ protons at $250 \mu \mathrm{A} \mathrm{cm} \mathrm{cm}^{2}$ (this experiment).

${ }^{\mathrm{b}} \phi_{\mathrm{T}}=2.7 \times 10^{11} \mathrm{n} / \mathrm{cm}^{2} \mathrm{~s}$.

$\mathrm{c}_{\phi_{T}}=4.7 \times 10^{16} \mathrm{n} / \mathrm{cm}^{2} \mathrm{~s}$. 


$$
\begin{aligned}
\mathbf{k}= & \text { Boltzman's constant } \\
\mathbf{b}= & \left.\begin{array}{l}
\text { constant }\left(=3.9 \times 10^{-\mathbf{s}} \mathrm{cm}^{2} /\right. \text { atom for } \\
\text { helium }
\end{array}\right) .
\end{aligned}
$$

For a bubble size of $95 A, \eta$ is calculated to be about 9400 helium atoms at $20^{\circ} \mathrm{C}$. This suggests that the cavities observed in the as-irradiated specimen probably contain helium atoms up to about $10 \sim$ $20 \%(1100 \sim 1800$ vs 9400$)$ of the equilibrium amount. For bubbles containing 1100 and 1800 helium atoms, the equilibrium bubble sizes at $20^{\circ} \mathrm{C}$ are 44 and $54 \mathrm{~A}$, respectively (see Table II).

Similar calculations presented in Table II have been made for the large cavities observed in the postirradiation-annealed specimens. At the annealing temperature of $250^{\circ} \mathrm{C}$, the equilibrium helium bubble size is 4.5 and $5.9 \mu \mathrm{m}$ for the helium concentration of 17.5 and 30 atomic ppm, respectively, while the observed cavity size is about $3.1 \mu \mathrm{m}$. Even though these numbers are only approximate because of the insufficient number of cavities observed and their large sizes and preferential occurrence at grain boundaries, it is suggestive that the large cavities are helium bubbles. At $425^{\circ} \mathrm{C}$, the calculated helium bubble size increases, while the observed cavity size is slightly reduced, as compared to $250^{\circ} \mathrm{C}$. This may be due to a loss of helium atoms during the thin-foil annealing carried out on this specimen.

\section{B. Comparison with Neutron Data}

The proton data of the present investigation are compared in Table III to the fission neutron data obtained from the literature on high-purity aluminum irradiated at similar temperatures and damage levels. The swelling is nearly the same, though the void density and size distribution differ. In particular, the void density is higher and the void size smaller than for the neutron irradiation. Figure 6 shows the proton swelling data on the same plot as neutron swelling data for high-purity aluminum. In Fig. 7, the void density from this study is plotted together with the data of Packan6,7 for neutronirradiated aluminum.

Several factors influence the differences in void density between the proton- and the neutronirradiated samples. Proton irradiation results in

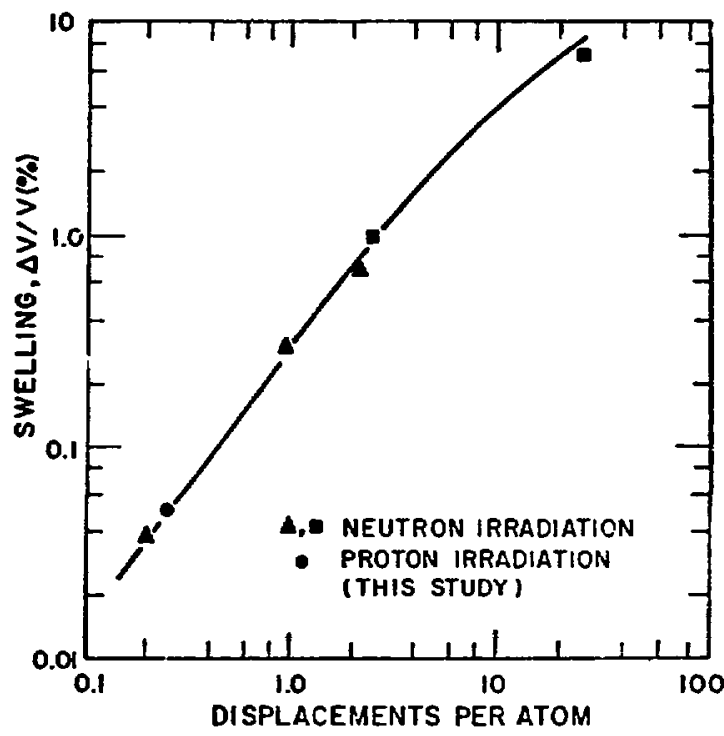

Fig. 6.

Void swelling is shown as a function of neutron fluence from the data of Packan 6 and Jostsons et al. 10 An additional point shows that the proton-induced swelling of this experiment lies on the same curve.

substantially higher helium and hydrogen production rates than does neutron irradiation, which

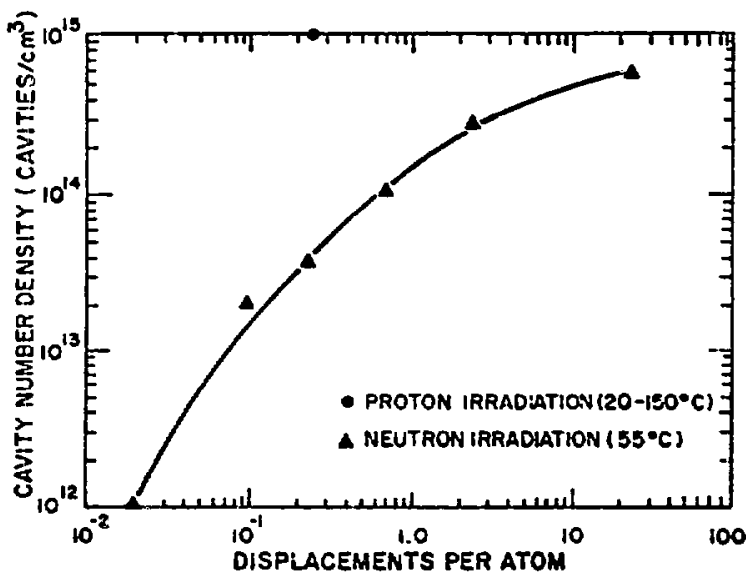

Fig. 7.

Variation of void number density in protonand neutron-irradiated high-purity aluminum as a function of dose. The neutron data are from Packan.6,? 
TABLE II

CAVITY AND HELIUM BUBBLE PARAMETERS IN PROTON-IRRADIATED ALUMINUM

\section{Experimental Cavity Parameters}

Experimental Cavity Parameters

$\mathbf{n}^{\mathrm{c}}$

\begin{tabular}{|c|c|c|c|c|c|c|}
\hline $\begin{array}{c}\text { Temp } \\
{ }^{\circ} \mathrm{C} \\
\end{array}$ & $\begin{array}{c}\mathbf{N}_{\mathrm{c}} \\
\text { Cavities/cm } \\
\end{array}$ & $\overline{\mathbf{d}}_{\mathrm{c}}$ & $\overline{\mathbf{D}}_{\mathrm{c}}{ }^{\mathrm{b}}$ & $\begin{array}{c}\Delta \mathbf{V} / \mathbf{V} \\
\% \\
\end{array}$ & $\begin{array}{c}\text { Helium } \\
\text { Atoms/ } \\
\text { Cavity }\end{array}$ & $\begin{array}{l}\text { Helium } \\
\text { Content } \\
\text { at. ppm }\end{array}$ \\
\hline 20 & 1. $\times 10^{16}$ & $89 A$ & $95 \mathrm{~A}$ & 0.05 & $9.4 \times 10^{3}$ & 157. \\
\hline 250 & $1.6 \times 10^{10^{0}}$ & $2.6 \mu \mathrm{m}$ & $3.1 \mu \mathrm{m}$ & $\sim 0.26$ & $3.1 \times 10^{\circ}$ & $\sim 8.2$ \\
\hline 425 & $1.3 \times 10^{10^{a}}$ & $2.6 \mu \mathrm{m}$ & $3.0 \mu \mathrm{m}$ & $\sim 0.19$ & $2.2 \times 10^{\circ}$ & $\sim 4.8$ \\
\hline
\end{tabular}

Calculated Helium B̉ubble Parameters

\begin{tabular}{|c|c|c|c|}
\hline \multicolumn{2}{|c|}{ for 17.5 at. ppm Helium } & \multicolumn{2}{|c|}{ for 30 at. ppm Helium } \\
\hline 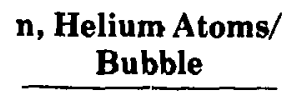 & Size, $D_{b}$ & $\mathbf{n}$ & $\overline{\mathbf{D}}_{\mathrm{b}}$ \\
\hline $\begin{array}{r}1.1 \times 10^{3} \\
\sim 6.6 \times 10^{\circ} \\
\sim 8.1 \times 10^{\circ}\end{array}$ & $\begin{array}{c}44 \mathrm{~A} \\
\sim 4.5 \mu \mathrm{m} \\
\sim 5.7 \mu \mathrm{m}\end{array}$ & $\begin{array}{c}1.8 \times 10^{0} \\
\sim 1.1 \times 10^{10} \\
\sim 1.4 \times 10^{10}\end{array}$ & $\begin{array}{c}54 \AA \\
\sim 5.9 \mu \mathrm{m} \\
\sim 7.5 \mu \mathrm{m}\end{array}$ \\
\hline
\end{tabular}

-Represents the upper limit; the overall average value was assumed to be two orders of magnitude lower than this.

$: \bar{D}_{c}=\left(\Sigma \mathrm{d}_{1} \mathrm{n}_{\mathrm{l}} / \Sigma \mathrm{n}_{1}\right)^{1 / 2}$

'Maximum number of helium atoms that can be contained in equilibrium.

Amount of helium necessary to fill the cavities with equilibrium gas.

TABLE III

IRRADIATION EFFECTS IN HIGH-PURITY ALUMINUM

\begin{tabular}{|c|c|c|c|c|c|c|c|c|c|}
\hline $\begin{array}{c}\text { Purity } \\
\text { Weight \% }\end{array}$ & $\begin{array}{c}\text { Irradiation } \\
\text { Temperature } \\
{ }^{\circ} \mathrm{C}\end{array}$ & $\begin{array}{l}\text { Type of } \\
\text { Irradiation }\end{array}$ & $\begin{array}{c}\text { Flux } \\
\text { n/cm }\end{array}$ & $\begin{array}{c}\text { Fluence } \\
n / \mathrm{cm}^{2}\end{array}$ & dpa & $\begin{array}{c}\mathbf{N}_{\mathrm{v}} \\
\text { Voids/cm }\end{array}$ & $d_{v}, A$ & $\begin{array}{c}\Delta V / V \\
\%\end{array}$ & Reference \\
\hline 99.999 & $20 \sim 150$ & $\mathbf{P}$ & & & 0.25 & $1.0 \times 10^{18}$ & 88 & 0.05 & This study \\
\hline 99.9999 & 55 & $n$ & $1.1 \times 10^{14}$ & $1.3 \times 10^{20}$ & 0.2 & $1.9 \times 10^{18}$ & 323 & 0.04 & 5,6 \\
\hline 99.9999 & 55 & $n$ & $10.9 \times 10^{14}$ & $1.6 \times 10^{20}$ & 0.2 & $3.8 \times 10^{12}$ & 244 & 0.03 & 5,6 \\
\hline 99.99996 & 55 & $n$ & $1.4 \times 10^{14}$ & $2.4 \times 10^{20}$ & 0.17 & $7.8 \times 10^{14}$ & 305 & 0.11 & 9 \\
\hline 99.994 & 55 & $n$ & $1.4 \times 10^{14}$ & $2.4 \times 10^{20}$ & 0.17 & 1. $\times 10^{18}$ & 285 & 0.014 & 9 \\
\hline
\end{tabular}


should increase the void density. The displacement rates are about the same for the proton-irradiated aluminum as for the neutron-irradiated material. Higher displacement rates generally result in a larger homogeneous void nucleation rate. In addition, impurities are known to reduce the void density, requiring consideration of the spallation impurities introduced.

The larger void density in proton-irradiated aluminum can be primarily attributed to the higher production rate of gaseous atoms in the proton irradiation, as shown in Table I. Farrell et al. ${ }^{8}$ observed an increase of void concentration in neutronirradiated aluminum samples preinjected with helium and hydrogen, and also found that helium is more effective than hydrogen. Packan 6 observed no profound effect of hydrogen on void formation in high-purity neutron-irradiated aluminum. Therefore, it is suggestive that the higher void number density observed in the present investigation is primarily due to the high helium production rate.

The void size of this siudy is smaller than the neutron data by a factor of about 3 ; however, the void volume fraction is almost the same. This implies that the same number of vacancies is involved in the voids both in the neutron and the proton irradiation, suggesting that the gaseous atoms influence only the void nucleation process. Therefore, for a constant vacancy supersaturation, the void growth rate will be reduced by a higher void nucleation rate which increases the competition between voids for the vacancies.

As mentioned previously, the void size distribution can also be altered by high fluxes 6 and impurities. ${ }^{9}$ The high flux effect is not comparable to the results of this study because even an order of magnitude higher flux only reduces the size by a factor of 2.6 Impurities are known ${ }^{9}$ to reduce both void size and swelling. Thus, the fact that the swelling was the same for this experiment and for neutron irradiation to the same damage level suggeste the spallation products generated during the proton irradiation have little effect on void formation at the damage levels reached in this study.

Finally, the void-annealing behavior of this study is consistent with that of Jostsons et al. ${ }^{10}$ who observed, in high-purity aluminum specimens irradiated to $1.6 \times 10^{21} \mathrm{n} / \mathrm{cm}^{2}$ at $55^{\circ} \mathrm{C}$, little or no void annealing at temperatures below about $200^{\circ} \mathrm{C}$, and a complete disappearance of all the smaller voids with sizes less than $200 \mathrm{~A}$ in diameter at temperatures of 250 to $275^{\circ} \mathrm{C}$.

\section{CONCLUSIONS}

1. Cavities are formed in Marz-grade aluminum ( $99.999 \%$ purity) irradiated by $800-\mathrm{MeV}$ protons to $0.25 \mathrm{dpa}$ at $20^{\circ} \mathrm{C}$, and the cavities are probably filled with helium gas up to $10 \sim 20 \%$ of the equilibrium amount.

2. High production rate of gas atoms during proton irradiation increases the cavity number density by an order of magnitude, and decreases the cavity size by a factor of about 3 , resulting in a degree of swelling comparable to neutron irradiation.

3. Gas atoms produced during proton irradiation seem to behave like preinjected gases in neutron irradiation in terms of influencing the void formation behavior.

4. Spallation products produced during proton irradiation seem to have little effect cis the void formation behavior.

5. An irradiation with $800-\mathrm{MeV}$ protons produces a uniformly damaged region through a bulk specimen.

6. No observable precipitates are formed during the proton irradiation.

7. Annealing behavisis of the proton-irradiationinduced cavities is consistent with that of neutronproduced voids.

8. Helium atoms produced during the proton irradiation form equilibrium gas bubbles on grain boundaries after a postirradiation anneal at $250^{\circ} \mathrm{C}$ and above.

\section{REFERENCES}

1. C. A. Coulter, D. M. Parkin, and W. V. Green, J. Nucl. Mater. 67, 140 (1977).

2. C. A. Coulter, private communication.

3. R. Blackburn, Met. Rev. 11, 159 (1966).

4. K. H. Westmacott, R. E. Smallman, and P. S. Dobson, Met. Sci. J. 2, 177 (1968). 
5. Handbook of Chemistry and Physics, 54th ed. (1973-74), D-157 (Ed. R. C. Weast, Chemical Rubber Co., Cleveland, Ohio).

6. N. H. Packan, J. Nucl. Mater. 40, 1 (1971).

7. J. O. Stiegler, "Radiation-Induced Voids in Metals," AEC Symp. Series 26, 292 (1972).
8. K. Farrell, A. Wolfenden, and R. T. King, Rad. Eff. 8, 107 (1971).

9. A. Risbet, G. Brebec, J. M. Lanore, and V. Levy, J. Nucl. Mater. 56, 348 (1975).

10. A. Jostsons, E. L. Long, Jr., J. O. Stiegler, K. Farrell, and D. N. Braski, "Radiation-Induced Voids in Matals," AEC Sýmp. Series 26, 363 (1972). 